\title{
A Case Report of Takayasu's Arteritis
}

\author{
Khan MAM ${ }^{1}$, Banoo $\mathrm{H}^{2}$
}

\begin{abstract}
Takayasu's arteritis, or "pulseless" disease is a rare, idiopathic, chronic granulomatous vasculitis that affects aorta and its major branches. This report describes a 57year-old man who presented with gradual loss of vision, syncopal attack and arm claudication. His ocular findings suggested bilateral ocular ischemic syndrome. He was later diagnosed as having Takayasu's disease.
\end{abstract}

\section{Introduction}

Takayasu's arteritis (TA), also known as aortoarteritis and pulseless disease, is a rare condition. It is a form of granulomatous arteritis, which affects large- and mediumsized arteries, primarily the aorta and its large branches as well as proximal portions of pulmonary, coronary, and renal arteries. Initially, there are mononuclear cell infiltrations in the adventitia and granulomas with Langerhans cells in the media, followed by disruption of the elastin layer and subsequent massive medial and intimal fibrosis. These lesions result in segmental stenosis, occlusion, dilatation, and aneurysmal formation in the affected vessels. Diminished or absent pulses are present in $84-96 \%$ of patients, associated with limb claudication and blood pressure discrepancies between the two arms ${ }^{1}$. The symptoms are secondary to the involved artery, and it may evolve into a life-threatening condition ${ }^{2,3}$. Involvement of the carotid artery results in ophthalmic artery hypoperfusion and causes ocular ischemic syndrome $e^{4}$.

This report describes a 57-year-old man who presented with gradual visual loss, syncopal attack and arm claudication. His ocular findings suggested bilateral ocular ischemic syndrome. He was later diagnosed as having Takayasu's disease.

\section{Case Report}

A 57-year-old man had a gradual decline in visual acuity over the past 3 months in both eyes. The medical history was positive for generalized fatigue, numbness and pain in the upper extremities particularly on the left arm that worsened on exertion resembled ischemic pain.

1. Dr. Md. Abdul Mahid Khan D-Card, MRCP

Assistant Professor of Cardiology

Bangladesh Institute of Health Science, Dhaka, Bangladesh

2. Corresponding Author:

Professor Dr. Hasina Banoo MBBS, FCPS, WHO fellow in Cardiology

Advisor Department of Cardiology

Bangladesh Institute of Health Science, Dhaka, Bangladesh
Brachial and radial arterial pulses of left side were absent on palpation. Right sided pulses were normal. His blood pressure was measured 150/90 in right arm but blood pressure was non recordable on left arm.

On ophthalmic examination, visual acuity was $6 / 36$ in the right eye and counting fingers at 2 meter in the left eye. Retinal examination showed microaneurysms, dot and blot hemorrhages, extensive ischemic area of retina in both eyes and new vessels at optic disc in left eye. Fundus fluorescein angiogram showed a delay in the arm-to-retina time (18 seconds), increased arterio-venous transit time and extensive area of capillary non-perfusion in both eyes and leakage from disc neovacularization in left eye. On the basis of all these findings an ophthalmologist made the diagnosis of bilateral ocular ischemic syndrome.

Laboratory findings showed an elevated erythrocyte sedimentation rate (ESR) of $46 \mathrm{~mm} / \mathrm{h}$ (normal value $<20$ $\mathrm{mm} / 1 \mathrm{~h}$ ) and serum C-reactive protein level of $1.13 \mathrm{mg} / \mathrm{dl}$ (normal value $<0.5 \mathrm{mg} / \mathrm{dl}$ ). Results of different laboratory tests were normal except mild rise of total serum lipid. Carotid Duplex Ultrasound and Angiogram showed total occlusion of left common carotid and left subclavian artery, partial obstruction of the right common carotid artery and normal aorta, brachiocephlic trunk and right subclavian artery. Coronary and renal angiogram was normal. On the basis of clinical manifestations and angiographic findings, the diagnosis of TA was made.

The patient was given oral steroids on a tapered basis. The patient underwent panretinal photocoagulation in both eyes. We consulted with vascular surgeons who have planned to do carotid endarterectomy on this patient.

\section{Discussion}

Takayasu's disease is seen in a wide geographic area, mainly in Asia and Africa. It is an autoimmune disease involving the arterial walls of large arteries, causing panarteritis ${ }^{2}$. The American Rheumatological Society considers three of the following six criteria necessary for a definite diagnosis of Takayasu's disease ${ }^{3}$ :

1. Onset before 40 years

2. Claudication of the extremities

3. Decrease in the brachial pulse in one or both arms

4. Difference of $10 \mathrm{~mm} \mathrm{Hg}$ or more in blood pressure measured in both arms

5. Audible bruit on auscultation of the aorta or subclavian artery

6. Narrowing at the aorta or its primary branches on arteriogram 
The current patient met five of the six criterias leaving the onset of the disease. Our patient was a 57 years old male. Though TA is predominantly a disease of young adults in the second and third decades of life, but not uncommon in childhood and in adults older than 40 years ${ }^{5,6,7}$. The youngest patient described was 6 months old ${ }^{7}$ and the oldest one was 75 years $^{8}$. Although females are more likely to be affected by this TA but males are also affected. In adults approximately $80 \%$ of patients with TA are women ${ }^{6}$, although the female-to-male ratio varied from 9:1 in reports from Japan ${ }^{9}$, 6.9:1 in Mexico to 1.2:1 in Israel $^{10}$.

Clinical manifestations of TA are nonspecific. The clinical course of the disease is divided into an early active inflammatory phase and late chronic phase. The active phase lasts for weeks to months and may have a remitting and relapsing course. It is characterized by systemic disease with symptoms of fever, general malaise, night sweats, loss of appetite, weight loss, headaches, dizziness, arthralgia, skin rashes, etc. The acute phase does not occur in all patients, but constitutional symptoms are often seen in children with TA. It should be highlighted that the correct diagnosis of TA is seldom made in the early phase. Evidence of vessel inflammation such as tenderness along arteries, bruits, and aneurysm may point to the diagnosis of $\mathrm{TA}^{5}$. The late chronic phase is the result of arterial stenosis and/or occlusion and ischemia of organs. Its clinical manifestations are varied and related to the location of arterial lesions ${ }^{5,11}$ as presented in Table ${ }^{1}$.

\section{Table 1: Clinical features of Takayasu arteritis related to ischemia}

\begin{tabular}{|c|c|}
\hline The vessels involved & Clinical features \\
\hline 1. Aortic branches & $\begin{array}{l}\text { Malaise, decreased or absent pulse } \\
\text { of upper extremities, dysfunction } \\
\text { of upper extremities, headaches, } \\
\text { dizziness, vision and orientation } \\
\text { disturbances, syncope }{ }^{12,13}\end{array}$ \\
\hline 2. Aortic arch & $\begin{array}{l}\text { Congestive heart failure, aortic } \\
\text { valve insufficiency, arterial } \\
\text { hypertension }{ }^{14,15,16}\end{array}$ \\
\hline 3. Coronary arteries & $\begin{array}{l}\text { Ischemic heart disease, } \\
\text { myocardial infarction }^{17,18}\end{array}$ \\
\hline 4. Pulmonary arteries & $\begin{array}{l}\text { Chest pain, dyspnea, coughing, } \\
\text { hemoptysis, congestive heart } \\
\text { failure }^{19}\end{array}$ \\
\hline $\begin{array}{l}\text { 5. Abdominal aorta or } \\
\text { celiac trunk }\end{array}$ & $\begin{array}{l}\text { Ischemia of the stomach and } \\
\text { intestines, abdominal pain, } \\
\text { nausea, vomiting }{ }^{20}\end{array}$ \\
\hline 6. Renal arteries & $\begin{array}{l}\text { Arterial hypertension, chronic } \\
\text { renal failure }\end{array}$ \\
\hline
\end{tabular}

Our patient presented with visual loss, malaise, absent pulses of left upper extremities, dysfunction of upper extremities, dizziness and syncope as he got occlusion and stenosis of branches of aorta. In $13.5 \%$ to $33 \%$ TA patient may present with visual loss ${ }^{24}$.
Suspected TA mandates vascular imaging. While the intraarterial angiography still remains the standard for diagnosis and evaluation of Takayasu arteritis, it has been largely replaced by computed tomography angiography or magnetic resonance angiography (MRA). Treatment of TA is based on the use of immunosuppressant such as prednisone and/or methotrexate to decrease or eliminate inflammatory activity. Anti-inflammatory therapy can lead to a dramatic improvement in TA. The 5-year survival rate in adults is as high as $94 \% 25$.

In the presence of symptomatic stenotic or occlusive lesions, endovascular revascularization procedures like bypass grafts, patch angioplasty, endarterectomy, percutaneous transluminal angioplasty, or stent placement should be taken into consideration ${ }^{23}$. The status of such treatment is controversial in the literature. Despite providing short-term benefit, endovascular revascularization procedures are associated with a high failure rate in patients with Takayasu's arteritis. Published results suggest that these procedures should be undertaken with great care and be reserved for specific indications. Both, surgical and endovascular, treatments become risky and achieve poorer outcomes, if they are undertaken during a period of inflammatory activity ${ }^{26}$.

Ophthalmic consequences should be considered, as with any other ocular ischemic syndrome, and extreme caution should be taken, especially when performing surgery.

\section{References}

1. Johnston SL, Lock RJ, Gompels MM. Takayasu arteritis: a review. J Clin Pathol 2002;55:481-6.

2. Chun YS, Park SJ, Park IK. The clinical and ocular manifestations of Takayasu arteritis. Retina. 2001;21:132-140.

3. Worrall M, Atebara N, Meredith T, Mann E. Bilateral ocular ischemic syndrome in Takayasu disease. Retina. 2001;21:75-76

4. Kohrman MH, Huttenlocher PR. Takayasu arteritis: a treatable cause of stroke in infancy. Pediatr Neurol. 1986;2:154-158.

5. Kothari SS. Takayasu's arteritis in children-a review. Images Paediatr Cardiol. 2002;9:4-23

6. Rossman MG Takayasu arteritis. http//emedicine.medscape.com/article332378-overview. Accessed 27 Sep 2011.

7. Hom C. Pediatric Takayasu arteritis. http//emedicine.medscape.com/article1007566-overview. Accessed 25 Aug 2010.

8. Lie JT. Segmental Takayasu (giant cell) aortitis with rupture and limited dissection. Hum Pathol. 1987;18:1183-1185.

9. Landhani S, Tulloh R, Anderson D. Takayasu disease masquerading as interruption of the aortic arch in a 2 year old child. Cardiol Young. 2001;11:244-246.

10. Brunner J, Feldman BM, Tyrrell PN, Kuemmerle-Deschner JB, Zimmehackl LB, Gassner I, Benseler SM. Takayasu arteritis in children and adolescents. Rheumatology (Oxford) 2010;49:1806-1814.

11. Ogino H, Matsuda H, Minatoya K, Sasaki H, Tanaka H, Matsumura $\mathrm{Y}$ et al. Overview of late outcome of medical and 
surgical treatment for Takayasu arteritis. Circulation. 2008; 118:2738-2747.

12. Kim HJ, Suh DC, Kim JK, Kim SJ, Lee JH, Choi CG et al. Correlation of neurological manifestations of Takayasu arteritis with cerebral angiographic findings. Clin Imaging. 2005;29:79-85.

13. Sugawara Y, Sueda T, Orihashi K, Okada K. Surgical treatment of atypical aortic coarctation associated with occlusion of all arch vessels in Takayasu's disease. Eur J Cardiothorac Surg. 2002;22:836-838.

14. Gerhardt RT, Lorenzo LA. Takayasu arteritis presenting as a recurrent respiratory tract infection: a diagnosis facilitated by bedside echocardiography and increased erythrocyte sedimentation rate. Mil Med. 2002;167:170-171.

15. Goodman D, Shulman S, Fenik J, Rowley A, Lane J, Rozenfeld $\mathrm{R}$ et. al. A 19-month- old girl with congestive heart failure, hypertension, and coronary artery dilatations. Interview by Robert Listernick. Pediatr Ann. 2005;34:14.

16. Landhani S, Tulloh R, Anderson D. Takayasu disease masquerading as interruption of the aortic arch in a 2 year old child. Cardiol Young. 2001;11:244-246.

17. Amano J, Suzuki A. Coronary artery involvement in Takayasu's arteritis. Collective review and guideline for surgical treatment. J Thorac Cardiovasc Surg. 1991;102:554560.

18. Dudina AL, Moore DP, Keogh B, Foley D, Graham IM. Chest pain and hypertension in an 18 year old girl. Ir Med J. 2008;101:285-286.
19. Karadag B, Kilic H, Duman D, Ongen Z, Vural VA, Yazici H. Takayasu disease with prominent pulmonary artery involvement: confusion with pulmonary disease leading to delayed diagnosis. Mod Rheumatol. 2008;18:507-510.

20. Arora P, Kher V, Singhal MK, Kumar P, Gulati S, Baijal SS et al. Renal artery stenosis in aortoarteritis: spectrum of disease in children and adults. Kidney Blood Press Res. 1997;20:285-289.

21. Borazan A, Sevindik OG, Solmaz D, Gulcu A, Cavdar C, Sifil A et al. Camsari A rare cause of renovascular hypertension: Takayasu arteritis with only renal artery involvement. Ren Fail. 2009;31:327-33.

22. Gumus B, Cevik H, Vuran C, Omay O, Kocyigit OI, Turkoz R. Cutting balloon angioplasty of bilateral renal artery stenosis due to Takayasu arteritis in a 5-year-old child with midterm follow-up. Cardiovasc Intervent Radiol. 2010;33:394-397.

23. Tyagi S, Khan AA, Kaul UA, Arora R. Precutaneous transluminal angioplasty for stenosis of the aorta due to aortic arteritis in children. Pediatr Cardiolol. 1999;20:404-410.

24. Sagar S, Kar S, Gupta A, Sharma BK. Ocular changes inTakayasu's arteritis in India. Jpn J Ophthalmol. 1994;38:97-102.

25. Koide K. Takayasu arteritis in Japan. Heart Vessels Suppl. 1992;7:48-54.

26. Tyagi S, Sharma VP, Arora R. Stenting of aorta for recurrent long stenosis due to Takayasu arteritis in a child. Pediatr Cardiol. 1999;20:215-217. 